Article

\title{
Screening of Popcorn Genotypes for Drought Tolerance Using Canonical Correlations
}

\author{
Samuel Henrique Kamphorst $1, * \mathbb{B}$, Gabriel Moreno Bernardo Gonçalves $1, * \mathbb{0}$, \\ Antônio Teixeira do Amaral Júnior ${ }^{1}{ }^{\circledR}$, Valter Jário de Lima ${ }^{1}{ }^{\circledR}$, Jhean Torres Leite ${ }^{1}$, \\ Kátia Fabiane Medeiros Schmitt ${ }^{1}{ }^{10}$, Divino Rosa dos Santos Junior ${ }^{1}$, Juliana Saltires Santos ${ }^{1}$, \\ Fábio Tomaz de Oliveira ${ }^{1}$, Caio Cézar Guedes Corrêa ${ }^{1}$, Weverton Pereira Rodrigues ${ }^{1,2}$ and \\ Eliemar Campostrini ${ }^{1}$ (D) \\ 1 Laboratório de Melhoramento Genético Vegetal, Centro de Ciências e Tecnologias Agropecuárias, \\ Universidade Estadual Norte Fluminense Darcy Ribeiro (UENF), Campos dos Goytacazes, \\ Rio de Janeiro 28013-602, Brazil; amaraljr@uenf.br (A.T.d.A.J.); valter_jario@hotmail.com (V.J.d.L.); \\ torresjhean@gmail.com (J.T.L.); kmedeirosschmitt@gmail.com (K.F.M.S.); \\ juniorifagro@gmail.com (D.R.d.S.J.); julianasaltiresdossantos@yahoo.com.br (J.S.S.); \\ tomaz_oft@yahoo.com.br (F.T.d.O.); caiocagronomo@gmail.com (C.C.G.C.); \\ wevertonuenf@hotmail.com (W.P.R.); campostenator@gmail.com (E.C.) \\ 2 Centro de Ciências Agrárias, Naturais e Letras, Universidade Estadual da Região Tocantina do Maranhão, \\ Estreito, Maranhão 65975-000, Brazil \\ * Correspondence: samuelkampho@hotmail.com (S.H.K.); gabriel.agrobio@gmail.com (G.M.B.G.); \\ Tel.: +55-(22)-3248-6025 (S.H.K. \& G.M.B.G.)
}

Received: 27 August 2020; Accepted: 1 October 2020; Published: 6 October 2020

\begin{abstract}
Getting around the damage caused by drought is a worldwide challenge, particularly in Brazil, given that economy is based on agricultural activities, including popcorn growing. The purpose of this study was to evaluate popcorn inbred lines under water stressed (WS) and well-watered (WW) conditions regarding agronomic attributes, root morphology, and leaf "greenness" index (SPAD index), besides investigating the viability of indirect selection by canonical correlations (CC) of grain yield (GY) and popping expansion (PE). Seven agronomic, six morphological root traits were evaluated and SPAD index at five different dates during grain filling. The WS (-29\% less water than WW) affected significantly the GY $(-55 \%)$, PE $(-28 \%)$, increased the brace and crown root density, and more vertically oriented the brace and crown angles. Higher SPAD index is associated with a higher yield, and these measures were the only ones with no significant genotype $\times$ water condition interaction, which may render concomitant selection for WS and WW easier. For associating the corrections of the different traits, CC proved to have better potential than simple correlations. Thus, the evaluation of SPAD index at 29 days after the anthesis showed the best CC, and based on the previous results of SPAD index, may be used regardless of the water condition.
\end{abstract}

Keywords: leaf greenness index; root morphology; water stress

\section{Introduction}

In Brazil, popcorn is a much appreciated and consumed food, especially associated with leisure time and movie theaters [1-5]. In view of the increased consumption of this type of grain, it will be necessary to expand the growing area of this crop and enhance genetic values to the cultivars to meet the rising demand for the product $[2,3,6]$. There is still a wide market to be developed for the growing of popcorn in Brazil, as the area planted has increased by $223 \%$ in the last five years [7].

Getting around the drought losses, which will be ever more frequent [8] due to climate change resulting from man-made actions [9], is a challenge for world agribusiness. For Brazil, whose economy 
is strongly based on large-scale agricultural activities, and annual advances towards new areas with unpredictable rain regimes, the negative effects are supposed to be worse. Drought is the abiotic factor that most limits the agricultural productivity of maize [10-14]. In Brazil, agricultural production is concentrated in the second growing season (February to July), after the soybean harvest [15]. This period also happens during the dry seasons and may contain strong variations in rainfall [8]. Consequently, there is urgency in selecting high productive genotypes under drought conditions, as well as identifying efficient traits for genotypic discrimination in environments with water stress.

Induction of leaf senescence is a mechanism of response of plants to water stress conditions [12,14]. Under soil water stress conditions, it is often seen that maize genotypes with delayed leaf senescence-stay green-are the highest productive ones, and that is why breeders select them as germplasm adapted to the soil water stress condition [16-20]. As stated by some authors, stay-green cultivars are the best option for drought-prone environments [21,22]. This characteristic can be easily measured by means of a spectrometric method, using SPAD index, an important tool for diagnosing plant stress [13,23-25]. Choosing the proper phenological stage for "greenness" index measurements is a major bottleneck, which is why the effective application of phenotyping methodologies has to do, in part, with the ability to apply them in critical stages associated with grain production [19].

When there are environmental constraints intrinsic to the soil-either water or nutritional-a good conformation of the root system architecture is essential for greater agricultural yield [26]. A root system adapted to the specific conditions of abiotic soil stress represents an agronomic advantage [27]. Maize genotypes with a deep and branched axial root system can access water in deeper layers, where water availability is greater [28]. According to Gao and Lynch (2016) [29], having fewer crown roots improves the water uptake capacity in maize plants under water stress.

As for the popcorn breeding for drought adaptation, in order to identify promising variables for indirect selection of grain yield and popping expansion, Kamphorst et al. (2019) [30] adopted the path analysis, and using the supertrait expanded popcorn volume per hectare as a dependent variable, they sought to get around the inconvenience of considering only one dependent variable for path analysis [31]. On the other hand, as it is a method of linear correlation between two multidimensional variables, the analysis of canonical correlations (CCA) turns out to be a more adequate statistical tool to uncover the relationships of the independent variables, when the focus is to quantify the association to more than one dependent variable. Moreover, the CCA takes into account the maximum correlation between two variable complexes [32], being a more viable option in comparison with the simple linear correlation, besides its implementation avoiding the obtaining of Type I error results [33].

The present study aimed at investigating the impact of water stress on agronomic traits, leaf greenness index, and root architectural traits of 20 popcorn inbred lines in two water conditions, and investigating the viability of using canonical correlations for the selection of easy-to-measure variables that are efficient predictors of grain yield and popping expansion.

\section{Materials and Methods}

\subsection{Plant Material}

It was evaluated a total of 20 popcorn lines $\left(\mathrm{S}_{7}\right)$, whose genealogy is derived from germplasm with tropical (L61, L63, L65, L69, L70, and L71-from the "BRS-Angela" population) and temperate/tropical climate adaptation (P1, P5, and P7-from the hybrid "Zélia"; P2 and P3-from the compound "CMS-42"; P4—from South American breeds; P6, P8, and P9—from the hybrid "IAC-112"; L54, L55, and L59—from the population "Beija Flor"; and L75 and L76-from the population "Barão de Viçosa") [34].

\subsection{Experimental Design, Cultural Traits, and Water Conditions Applied}

The experiments were conducted at the Experimental Station of the Colégio Estadual Agrícola Antônio Sarlo, in Campos dos Goytacazes city, Rio de Janeiro State, Brazil (Latitude $21^{\circ} 42^{\prime} 48^{\prime \prime}$ S, Longitude $41^{\circ} 20^{\prime} 38^{\prime \prime} \mathrm{O}, 14 \mathrm{~m}$ altitude). The soil of the Experimental Station has been classified as 
dystrophic Ultisol, presenting high levels of clay and silt. Trials were performed in the 2016 crop year, during the dry seasons, which include the period from April to August. Sowing was done on 10 April, and harvesting was carried out on 15 August.

The basal dressing application of fertilizers was made using $30 \mathrm{~kg} \mathrm{ha}^{-1}$ of $\mathrm{N}$ (in the form of urea), $60 \mathrm{~kg} \mathrm{ha}^{-1}$ of $\mathrm{P}_{2} \mathrm{O}_{5}$ (triple superphosphate), and $60 \mathrm{~kg} \mathrm{ha}^{-1}$ of $\mathrm{K}_{2} \mathrm{O}$ (potassium chloride). Top-dressing fertilization occurred 30 days after sowing (DAS), and $100 \mathrm{~kg} \mathrm{ha}^{-1}$ of $\mathrm{N}$ (in the form of urea) were applied.

Experimental plots comprised four $4.40 \mathrm{~m}$ long rows spaced $0.20 \mathrm{~m}$ apart between plants and $0.80 \mathrm{~m}$ between rows, totaling a density of 62,500 plants per hectare. The useful area of the plot was defined by $6.72 \mathrm{~m}^{2}$ of the central rows. An experimental randomized complete block design with three replicates in each water condition; that is, well-watered (WW) and water stressed (WS) was conducted. The analyses of variance were performed considering genotypes effect as fixed and block affect as random.

Irrigation was used for both water regimes by using a drip system. One Katif dripper per plant was installed with a flow rate of $2.3 \mathrm{~mm} \mathrm{~h}^{-1}$. Water condition 1 -well-watered (WW) was irrigated to maintain field capacity $(-10 \mathrm{kPa})$, which was monitored using Decagon MPS-6 (Decagon, USA) tensiometers applied to the soil between plants at a depth of $0.20 \mathrm{~m}$. Water condition 2-water stress (WS) was characterized by the suspension of irrigation at a phenological stage of male pre-anthesis. The soil reached the permanent wilting point $(-1500 \mathrm{kPa}) 12$ days after the male anthesis (data not presented).

In WS condition, irrigation was interrupted 49 days after sowing (DAS), remaining this way until harvest (119 DAS). At 56, 70, 77, 105, 112, and 119 DAS, rainfall was recorded, totaling $92 \mathrm{~mm}$ during this period. Plants of WW condition were given an additional $78 \mathrm{~mm}$ of water via drip during the same period, totaling $170 \mathrm{~mm}$ (Figure 1a).
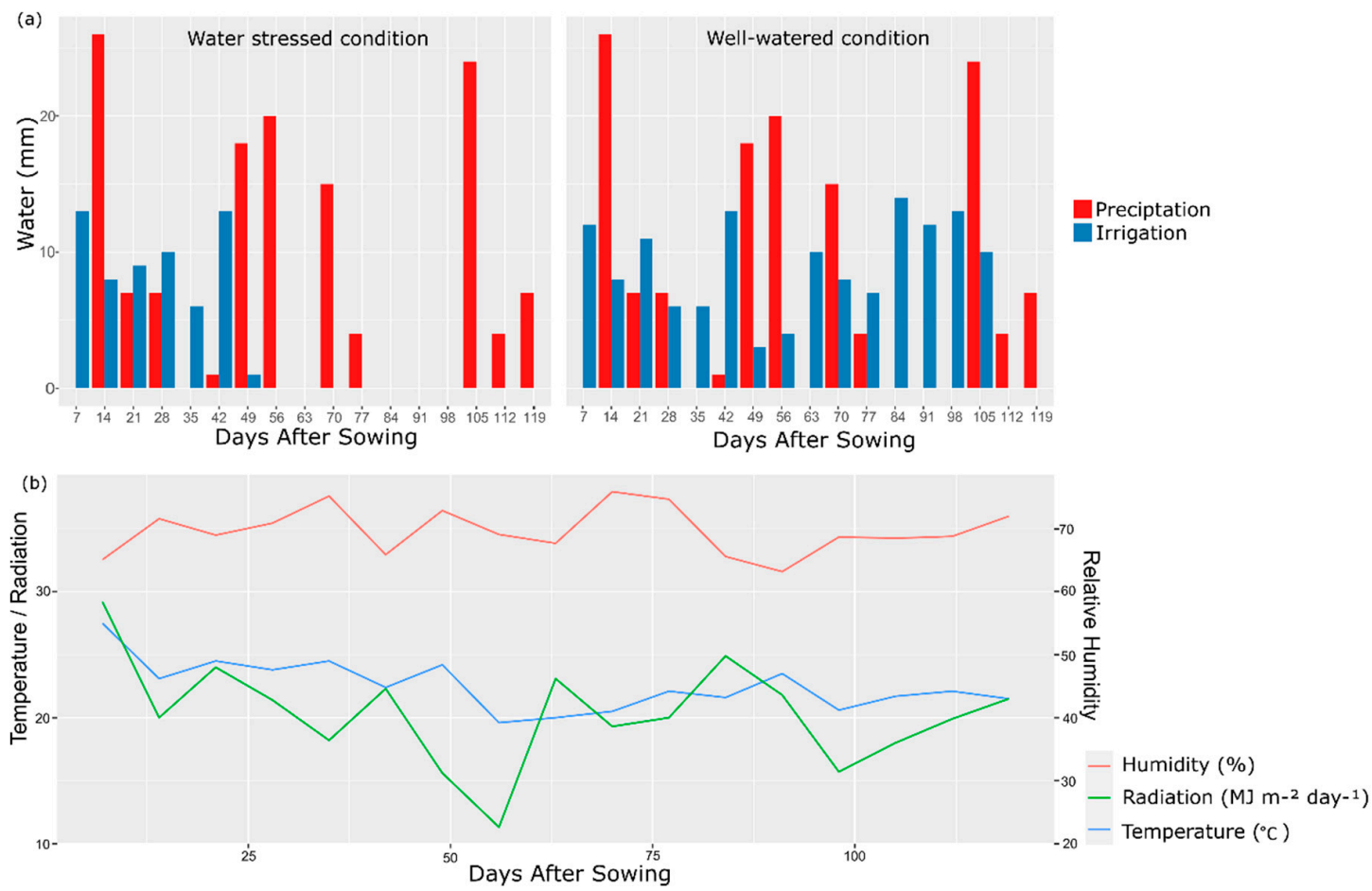

Figure 1. (a) Precipitation occurs during a trial conducted with 20 popcorn lines under well-watered condition and water-stressed condition. (b) Humidity, solar radiation, and temperature values measured in water stressed and well-watered conditions. 
Throughout the crop growth and development cycle, temperature and relative humidity ranged from $12{ }^{\circ} \mathrm{C}$ to $37^{\circ} \mathrm{C}$ and $23 \%$ to $97 \%$, respectively, with a mean solar radiation of $20.35 \mathrm{MJ} \mathrm{m}^{-2} \mathrm{day}^{-1}$ (maximum radiation at the experiment location was $1300 \mu \mathrm{mol} \mathrm{m}^{-2} \mathrm{~s}^{-1}$ (Figure 1b). Weather conditions were recorded in a weather station of the National Institute of Meteorology (INMET, in Portuguese), installed less than $100 \mathrm{~m}$ away from the experimental area.

\subsection{Traits Evaluated}

Traits were divided into three groups, or trait complex. The reference group, i.e., the so-called agronomic traits (AGRO), is the one related to grain yield and popping expansion. The group of root morphological traits (ROOT) includes the ones measured in the root system, specifically in the brace and crown roots. The third group is related to the intensity of leaf greenness (SPAD index) measured on different dates during the grain filling period.

The agronomic traits (AGRO) evaluated were grain yield (GY), popping expansion (PE), prolificacy (PR), 100-grain mass (HG), ear diameter (ED), ear length (EL), and dry matter weight (DM).

Grain yield (GY), obtained by harvesting all the plants in the useful area of the plot, was corrected to $13 \%$ humidity, and expressed in $\mathrm{kg} \mathrm{ha}^{-1}$. Popping expansion (PE) was measured for a mass of $30 \mathrm{~g}$ of grains, heated by microwaves, in a special paper bag for popping, at a 1000-watt power, for a time of two minutes and fifteen seconds, and the volume of popcorn was measured in a $2000 \mathrm{~mL}$ graduated cylinder. Popping expansion (PE) was determined by the quotient of the volume obtained from popcorn and grain mass expressed in $\mathrm{mL} \mathrm{g}^{-1}$. Prolificacy (PR) was established by counting the ears and expressed in mean values by the quotient of the number of ears harvested and the total number of plants in the plot. The 100-grain mass (HG) was obtained by weighing (g) three subsamples of 100 seeds each. A random sample of six plants from the plot was used to estimate the ear diameter (ED) and the ear length (EL), quantified by a caliper $(\mathrm{cm})$, and to determine the aerial dry matter (DM) by weighing (g) after drying in a hot air oven at $70{ }^{\circ} \mathrm{C}$ for $72 \mathrm{~h}$.

The root system traits evaluated were brace root number (BN), brace root angle (BA), brace root density (BD), crown root number (CN), crown root angle (CA), and crown root density (CD).

The root architectural traits were quantified following the methodology suggested by Traschel et al. (2011) [27], with modifications. After harvesting, the soil of the different water conditions (WW and WS) received 50-mm irrigation, to make it easier to remove the plants mechanically with the use of shovels. The root system of two plants per plot was removed in a $40-\mathrm{cm}$ diameter and $25-\mathrm{cm}$ deep soil cylinder. The roots in the soil cylinders were washed until the soil was completely removed. From the root categories-brace (B) and crown (C), the traits measured were root angle (A) (BA and $\mathrm{CA})$, obtained using a degree protractor and expressed in relation to the soil $\left({ }^{\circ}\right)$; root number $(\mathrm{N})(\mathrm{BN}$ and $\mathrm{CN}$ ), obtained by counting the structures; and mean density (D) of lateral roots (BD and CD), obtained using a diagrammatic scale proposed by Trachsel et al. (2011) [27]. Root density values vary from 1 to 9 , in which higher values indicate higher density.

The trait associated with the intensity of leaf greenness (SPAD index) was estimated by three readings in the middle third of the third leaf counted from the apex and below the flag leaf by means of the portable chlorophyll meter, model SPAD-502 "Soil Plant Analyzer Development" (Minolta, Japan). The SPAD index were measured on five different days after male anthesis (DAA), as follows: 17 DAA $\left(\mathrm{S}_{1}\right), 22 \mathrm{DAA}\left(\mathrm{S}_{2}\right), 29 \mathrm{DAA}\left(\mathrm{S}_{3}\right), 36 \mathrm{DAA}\left(\mathrm{S}_{4}\right)$, and $42 \mathrm{DAA}\left(\mathrm{S}_{5}\right)$. Measurements were taken when the soil water potential was below the permanent wilting point (>-1500 kPa) (data not provided). SPAD index was measured in a random sample of six useful plants of the experimental plot.

\subsection{Analysis of Variance and Statistical_Genetic Parameters}

The analysis of variance was individually performed for each water condition (WS and WW) taking into account the linear model: $\mathbf{y}_{\mathrm{ij}}=\boldsymbol{\mu}+\mathbf{g}_{\mathbf{i}}+\mathbf{b}_{\mathbf{j}}+\mathbf{e}_{\mathbf{i j}}$, in which the mean $(\boldsymbol{\mu})$ and genotype effect $\left(\mathbf{g}_{\mathbf{i}}\right)$ were considered to be fixed; and block $\left(\mathbf{b}_{\mathbf{j}}\right)$ and error $\left(\mathbf{e}_{\mathbf{i j}}\right)$, random. 
The statistical-genetic parameters coefficient of variation $(C V)$ and heritability $\left(\mathbf{H}^{2}\right)$ were estimated from the individual analyses by the estimators: $C V=\sqrt{M S e} / \mu \times 100$, in which MSe is the mean square of error; and $\mathbf{H}^{2}=M S g-M S e / M S g$, in which $M S g$ is the mean square of the genotype effect.

To verify the occurrence of genotype interaction with water conditions, a joint analysis was carried out by considering the following linear model: $y_{i j k}=\mu+g_{i}+w_{j}+g_{i j}+b / w_{j k}+e_{i j k}$, in which the mean $(\boldsymbol{\mu})$, the genotype effect $\left(\mathbf{g}_{\mathbf{i}}\right)$, and the water condition effect $\left(\mathbf{w}_{\mathbf{j}}\right)$ were considered to be fixed, and the block within condition effect $\left(\mathbf{b} / \mathbf{w}_{\mathbf{j k}}\right)$ and the error $\left(\mathbf{e}_{\mathbf{i j k}}\right)$, as random.

\subsection{Correlation Analysis}

For each water condition, a simple linear correlation analysis was applied using the Pearson method, involving all variables between themselves using the following model: $r=\sigma_{x y}^{2} / \sigma_{x}^{2} \times \sigma_{y}^{2}$, in which $r$ is the phenotypic correlation coefficient between variables $x$ and $y, \sigma_{x y}^{2}$ is the phenotypic covariance between variables $x$ and $y, \sigma_{x}^{2}$ is the phenotypic variance of $x$, and $\sigma_{y}^{2}$ is the phenotypic variance of $y$.

Existing correlations between trait complex were estimated by means of the canonical correlation analysis, taking into account the following groups: AGRO $\times$ ROOT traits and AGRO $\times$ SPAD traits.

The canonical correlations were estimated by combining the covariances within and between the traits of the variable complexes of the two groups $\left(\mathbf{S}_{11}, \mathbf{S}_{22}\right.$, and $\left.\mathbf{S}_{12}\right)$ and the weight of the traits of each

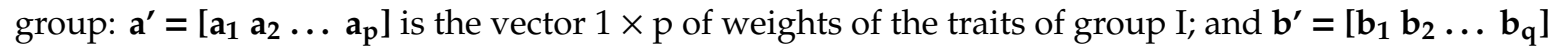
is the vector $1 \times q$ of weights of the traits of group II.

The first canonical correlation is defined by that which maximizes the relationship between $X_{1}$ and $Y_{1}$ by means of the expression:

$r_{1}=\operatorname{Cô} v\left(X_{1}, Y_{1}\right) / \sqrt{\hat{V}\left(X_{1}\right)} \cdot \hat{V}\left(Y_{1}\right)$, in which $\operatorname{Cô} v\left(X_{1}, Y_{1}\right)=a^{\prime} S_{12} b ; \hat{V}=a^{\prime} S_{11} a ; \hat{V}=b^{\prime} S_{22} b$.

The simple linear and canonical correlations were separately estimated for the means obtained in water condition (WS and WW), so they could be compared. The multicollinearity diagnostic among the traits in each pair of variable complexes was carried out based on the ratio between the highest and lowest eigenvalue of the inverse matrix and interpreted by the classification of Montgomery and Peck (1981) [35]. All statistical analyses were conducted in the GENES software [36].

\section{Results}

3.1. Genetic Variability and Effects of Different Water Conditions on SPAD Index and Agronomic (AGRO) and Root (ROOT) Traits

There is genetic variability among genotypes evaluated in both water conditions (WS and WW) for all agronomic traits, for the different times of greenness index measurements (SPAD index) and for traits related to the root system, except BN in WW condition. The experimental coefficient of variation (CV) was below $30.0 \%$ for the traits under evaluation. Generally, it was noted that the CV values were lower for the agronomic and root system traits under WS condition and for the different moments of SPAD index under WW condition (Table 1). 
Table 1. Summary of analysis of variance, means, coefficients of variation $(\mathrm{CV})$, and coefficient of genotypic determination of agronomic traits $\left(\mathrm{H}^{2}\right)$, different dates of measurement of greenness (SPAD index), and traits related to the root system evaluated in popcorn lines under water-stressed (WS) and well-watered (WW) conditions.

\begin{tabular}{|c|c|c|c|c|c|c|c|c|c|c|c|c|c|c|}
\hline \multirow{4}{*}{ Traits } & \multicolumn{12}{|c|}{ Water Condition (WC) } & \multicolumn{2}{|c|}{ Mean Squares (MS) of Joint Analysis } \\
\hline & \multicolumn{6}{|c|}{ Water Stressed (MS) } & \multicolumn{6}{|c|}{ Well Watered (MS) } & \multirow{2}{*}{ WC } & \multirow{2}{*}{ Genotype $\times$ WC } \\
\hline & Block & Genotype & Error & & & & Block & Genotype & Error & & & & & \\
\hline & $(\mathrm{DF}=2)$ & $(\mathrm{DF}=19)$ & $(\mathrm{DF}=38)$ & Mean & $\mathrm{CV} \%$ & $\mathrm{H}^{2}$ & $(\mathrm{DF}=2)$ & $(\mathrm{DF}=19)$ & $(\mathrm{DF}=38)$ & Mean & $\mathrm{CV} \%$ & $\mathrm{H}^{2}$ & $(\mathrm{DF}=1)$ & $(\mathrm{DF}=19)$ \\
\hline \multicolumn{15}{|c|}{ Agronomic traits (AGRO) } \\
\hline GY & 137418 & $55,9525 * *$ & 66,624 & 1139.11 & 22.65 & 88.09 & 60,1287 & $1,839,610$ ** & 336,794 & 2548.07 & 22.77 & 81.69 & $5.9 \times 10^{7 * *}$ & $70.2 \times 10^{5 *}$ \\
\hline PE & 2.75 & $36.4^{* *}$ & 3.35 & 20.91 & 8.75 & 90.79 & 2.52 & $52.27 * *$ & 16.39 & 29.35 & 13.79 & 68.62 & $2136.4 * *$ & $28.35^{* *}$ \\
\hline PR & 0.00 & 0.031 * & 0.01 & 0.86 & 14.08 & 53.22 & 0.10 & 0.060 ** & 0.02 & 1.02 & 12.32 & 73.64 & $0.785 *$ & $0.073 * *$ \\
\hline HG & 0.89 & $5.533 * *$ & 0.53 & 9.69 & 7.49 & 90.44 & 1.33 & $5.52 * *$ & 1.72 & 12.67 & 10.36 & 68.75 & $265.9^{* *}$ & $1.71^{\mathrm{ns}}$ \\
\hline ED & 9.04 & $20.06 * *$ & 2.75 & 27.94 & 5.94 & 86.27 & 10.59 & $17.70^{* *}$ & 2.39 & 29.12 & 5.31 & 86.46 & $41.8^{* *}$ & $3.45^{* *}$ \\
\hline EL & 3.38 & $6.18 * *$ & 1.14 & 12.62 & 8.46 & 81.49 & 2.97 & $5.57 * *$ & 0.81 & 12.72 & 7.10 & 85.34 & $0.25^{\mathrm{ns}}$ & $0.79^{\text {ns }}$ \\
\hline DM & 521.8 & $6812.3 * *$ & 1807.8 & 313.94 & 13.54 & 73.46 & $21,931.2$ & $10,358.4^{* *}$ & 2557.9 & 368.31 & 13.73 & 75.31 & $8.8 \times 10^{4 *}$ & $2614^{\mathrm{ns}}$ \\
\hline \multicolumn{15}{|c|}{ SPAD index } \\
\hline S1(17DAA) & 33.39 & $31.77^{* *}$ & 9.35 & 43.54 & 7.02 & 70.55 & 15.79 & $53.35^{* *}$ & 4.66 & 48.83 & 4.42 & 91.25 & $838^{* *}$ & $6.40^{\mathrm{ns}}$ \\
\hline S2(22DAA) & 17.23 & $63.53^{* *}$ & 8.45 & 40.32 & 7.21 & 86.69 & 9.03 & $38.32 * *$ & 7.10 & 48.96 & 5.44 & 81.47 & 2239 ** & $9.81^{\mathrm{ns}}$ \\
\hline S3(29DAA) & 1.52 & $64.42 * *$ & 8.88 & 39.70 & 7.50 & 86.20 & 24.45 & $37.26 * *$ & 4.59 & 48.15 & 4.45 & 87.67 & 2145 ** & $7.68^{\mathrm{ns}}$ \\
\hline S4(36DAA) & 30.62 & $100.18^{* *}$ & 22.51 & 32.50 & 14.59 & 77.52 & 34.45 & $59.94 * *$ & 9.69 & 45.98 & 6.77 & 83.82 & $5452 * *$ & $24.11^{\mathrm{ns}}$ \\
\hline S5(42DAA) & 39.71 & $82.73^{* *}$ & 24.20 & 18.81 & 26.15 & 70.74 & 49.96 & $108.62 * *$ & 13.30 & 39.35 & 9.26 & 87.75 & $12663 * *$ & $45.84^{* *}$ \\
\hline \multicolumn{15}{|c|}{ Root traits (ROOT) } \\
\hline BN & 0.53 & $6.472 * *$ & 0.50 & 9.12 & 7.75 & 92.27 & 2.77 & $3.94^{\text {ns }}$ & 2.79 & 8.67 & 19.25 & 29.27 & $6.03^{\mathrm{ns}}$ & $5.15 * *$ \\
\hline BA & 14.82 & $71.01 * *$ & 8.12 & 50.23 & 5.67 & 88.55 & 7.89 & $243.40^{* *}$ & 31.45 & 37.20 & 15.07 & 87.07 & $5094 * *$ & $48.73 * *$ \\
\hline BD & 0.00 & $4.002 * *$ & 0.16 & 5.98 & 6.75 & 95.91 & 0.14 & $4.276^{\text {** }}$ & 0.31 & 5.26 & 10.66 & 92.63 & $15.95^{* *}$ & $1.43^{* *}$ \\
\hline $\mathrm{CN}$ & 2.60 & $14.82 * *$ & 1.61 & 16.29 & 7.78 & 89.13 & 1.02 & $7.16^{* *}$ & 1.52 & 15.31 & 8.05 & 78.74 & $28.8^{\mathrm{ns}}$ & $6.01 * *$ \\
\hline CA & 4.33 & 83.81 ** & 9.08 & 53.08 & 5.67 & 89.16 & 9.30 & 166.32 ** & 11.10 & 42.63 & 7.81 & 93.32 & 3276 ** & $38.84 * *$ \\
\hline CD & 0.07 & $4.737^{* *}$ & 0.14 & 5.62 & 6.64 & 97.05 & 0.40 & 2.836 ** & 0.20 & 4.12 & 10.86 & 92.91 & 67.45 ** & $1.76^{* *}$ \\
\hline
\end{tabular}

MS: mean squares; WC: water condition; DF: degrees of freedom; GY: grain yield (Kg ha ${ }^{-1}$ ); PE: popping expansion (mL g $\left.{ }^{-1}\right)$; PR: prolificacy; HG: 100-grain mass (g); ED: ear diameter $(\mathrm{mm})$; EL: ear length (cm); DM: dry matter (g); S1, S2, S3, S4 e S5 = SPAD index at 17, 22, 29, 36 and 42 days after male anthesis, respectively; root traits: BN: brace number; BA: brace angle $\left({ }^{\circ}\right)$; BD: brace density; CN: crown number; CA: crown angle $\left({ }^{\circ}\right)$ and CD: crown density. Symbols ${ }^{\text {ns }},{ }^{*}$, and ${ }^{* *}$ represent not significant, significant at $5.0 \%$, and $1.0 \%$ probability, by the $\mathrm{F}$ test, respectively. 
Among the agronomic traits, grain yield (GY), popping expansion (PE), and 100-grain mass (HG) presented higher heritability $\left(\mathrm{H}^{2}\right)$ under WS condition, while the other ones-namely, prolificacy (PR), ear diameter (ED), ear length (EL), and dry matter weight (DM) - presented higher $\mathrm{H}^{2}$ under WW condition. Under the WS condition, the means of GY and PE were reduced by $55.3 \%$ and $28.7 \%$ compared with WW condition, respectively. Only the EL did not present a significant difference in mean between the different water conditions (WC). The means of PR, ED, and DM were significantly lower under WS condition, in the order of $15.7 \%, 4.1 \%$, and $14.8 \%$, respectively (Table 1 ). Significant genotype $\times$ water condition (Gen $\times$ WC) interactions were observed in GY, PE, PR, and ED (Table 1).

The SPAD index, under WW condition, presented higher values of $\mathrm{H}^{2}$ in the different measurement dates regarding WS condition. Given the comparison of WS and WW condition, the proportional mean reductions were $10.8 \%\left(\mathrm{~S}_{1}\right), 17.6 \%\left(\mathrm{~S}_{2}\right), 17.5 \%\left(\mathrm{~S}_{3}\right), 29.3 \%\left(\mathrm{~S}_{4}\right)$, and $52.2 \%\left(\mathrm{~S}_{5}\right)$ for the measurements taken 17, 22, 29, 36, and 42 days after the anthesis (DAA). In the joint analysis, a difference was seen between the means of SPAD index between water conditions, with significance in the Gen $\times$ WC interaction only in the measurement carried out at 42 days $\left(\mathrm{S}_{5}\right)$ (Table 1$)$.

With respect to root traits (ROOT), apart from the crown root angle (CA), $\mathrm{H}^{2}$ were superior under WS condition. The mean of brace root (BN) and crown $(\mathrm{CN})$ number did not differ in both water conditions; all other root traits, however, expressed means with higher values under WS condition. In the joint analysis, a significant Gen $\times$ WC interaction was noted for all root traits (Table 1).

3.2. Phenotypic Correlations within and among AGRO, SPAD Index, and ROOT Trait Groups under WS and WW Conditions

Correlations of greater expression, all in positive direction, among the traits of the AGRO group were seen between GY $\times \mathrm{ED}(0.43), \mathrm{GY} \times \mathrm{EL}(0.40)$, and $\mathrm{ED} \times \mathrm{DM}(0.42)$, under WS condition, and between GY $\times \mathrm{ED}(0.50), \mathrm{GY} \times \mathrm{EL}(0.52), \mathrm{PE} \times \mathrm{PR}(0.40), \mathrm{ED} \times \mathrm{DM}(0.49)$, and $\mathrm{ED} \times \mathrm{DM}(0.49)$, under WW condition (Figure 2).
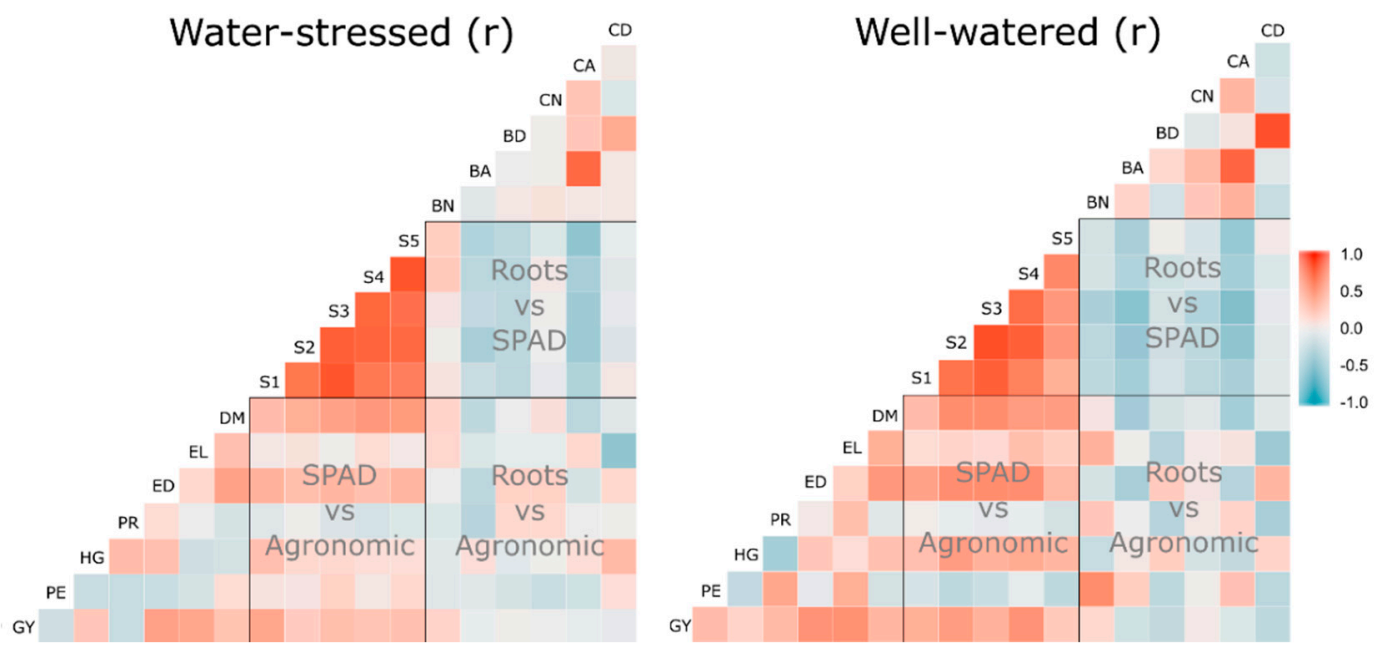

Figure 2. Phenotypical correlation among 18 traits evaluated in 20 popcorn inbred lines under two different water conditions. Agronomic traits-GY: grain yield; PE: popping expansion; PR: prolificacy; HG: 100-grain mass; ED: ear diameter; EL: ear length and DM: dry matter). SPAD index- $S_{1}, S_{2}, S_{3}, S_{4}$, and $S_{5}=$ SPAD index at 17, 22, 29, 36, and 42 days after male anthesis, respectively; Roots traits-BN: brace number; BA: brace angle; $\mathrm{BD}$ : brace density; $\mathrm{CN}$ : crown number; $\mathrm{CA}$ : crown angle and $\mathrm{CD}$ : crown density.

Correlations among the traits of the AGRO and SPAD index groups were more expressive under WW condition. All associations observed between GY $\times \mathrm{S}_{4}(0.51), \mathrm{ED} \times \mathrm{S}_{2}(0.53), \mathrm{ED} \times \mathrm{S}_{3}(0.54)$, and $\mathrm{ED} \times \mathrm{S}_{4}(0.53)$ were positive. Under WS condition, the most intense association estimate occurred between $G Y \times S_{1}(0.40)$. 
The correlation of greater expression between the traits of the AGRO and ROOT group, under WW condition, in positive direction, occurred between $\mathrm{PE} \times \mathrm{BN}(0.54)$ and, under WS condition, in negative direction, between EL $\times$ CD (-0.46) (Figure 2).

Correlations between the traits of the SPAD index and ROOT group mainly denote negative associations under WW condition. The leaf greenness index, measured 22 DAA $\left(\mathrm{S}_{2}\right)$, was moderately correlated with CA $(-0.46)$, and the one measured 29 DAA $\left(S_{3}\right)$ was more intensely associated with BA (-0.48) and CA (-0.53). Under WS condition, the CA trait was correlated with $S_{2}$ (22 DAA), $\mathrm{S}_{3}(29 \mathrm{DAA})$, and $\mathrm{S}_{5}(42 \mathrm{DAA})$, with values of $-0.40,-0.39$, and -0.45 , respectively (Figure 2 ).

The traits of the SPAD group showed high correlations between themselves, irrespective of the water condition. Regarding the ROOT group, it was observed a high correlation between $\mathrm{BA} \times \mathrm{CA}$, under both water conditions, $(\approx 0.72)$, while the correlation between $\mathrm{BD} \times \mathrm{CD}(0.82)$ was expressive only under WW condition.

\subsection{Canonical Correlations among AGRO, SPAD Index, and ROOT Trait Groups in WS and WW Conditions}

The multicollinearity classification applied to the phenotypic correlation matrix between the two pairs of variable complexes presented a week multicollinearity for the pair AGRO and ROOT, and moderate for the pair AGRO and SPAD. For that reason, the canonical correlation analysis (CCA) could be carried out with the traits evaluated [37].

There were significant correlations between AGRO and SPAD index groups of traits under both water conditions (WS and WW) (Table 2). The correlation was significant in the first three canonical pairs under WS condition. In the first canonical pair $(\mathrm{r}=0.92)$, the variable DM was associated in the opposite direction with the SPAD index in $\mathrm{S}_{1}$ (17 DAA) and in the same direction with $\mathrm{S}_{2}$ (22 DAA). The second canonical pair $(r=0.74)$ associated higher GY values and lower EL values with higher $S_{1}$ values and lower $S_{3}$ values. The third canonical pair $(r=0.68)$ associated PE with all measurement dates of the SPAD index, pointing out that higher values in $S_{1}, S_{3}$, and $S_{5}$ and lower $S_{2}$ and $S_{4}$ were related to the lower PE (Table 2).

Table 2. Correlation and coefficients of canonical pairs estimated between SPAD index and agronomic traits in 20 popcorn inbred lines under two different water conditions.

\begin{tabular}{|c|c|c|c|c|c|c|c|c|c|c|c|}
\hline & \multirow{3}{*}{ Traits } & \multicolumn{10}{|c|}{ Canonical Pairs } \\
\hline & & \multicolumn{5}{|c|}{ Water-Stressed } & \multicolumn{5}{|c|}{ Well-Watered } \\
\hline & & 1st & 2nd & 3 rd & 4th & 5 th & 1st & 2nd & 3 rd & 4th & 5 th \\
\hline \multirow{5}{*}{ 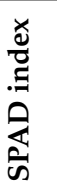 } & S1(17DAA) & -1.16 & 1.74 & 1.19 & -0.13 & 0.12 & 1.14 & 0.82 & -0.34 & 1.43 & -0.49 \\
\hline & S2(22DAA) & 2.14 & -0.07 & -0.92 & -1.42 & 2.18 & 0.01 & -1.22 & 1.41 & 0.61 & -1.63 \\
\hline & S3(29DAA) & -0.33 & -1.64 & 1.05 & 2.04 & -1.19 & 0.03 & 0.09 & 0.79 & -1.86 & 2.41 \\
\hline & S4(36DAA) & 0.04 & 0.45 & -1.84 & 0.50 & -0.97 & -2.55 & -0.34 & -0.31 & 2.46 & 0.51 \\
\hline & S5(42DAA) & -0.10 & 0.27 & 1.20 & -0.80 & -0.63 & 1.20 & 1.48 & -0.90 & -2.51 & -1.00 \\
\hline \multirow{10}{*}{ 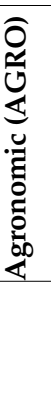 } & GY & 0.32 & 1.78 & -0.30 & -0.76 & 0.06 & -0.14 & -0.68 & 2.10 & 1.03 & 1.33 \\
\hline & PE & 0.13 & -0.45 & -0.81 & 0.25 & 0.17 & 0.27 & 0.02 & 0.62 & -0.12 & 0.09 \\
\hline & PR & 0.33 & -0.15 & -0.16 & 0.33 & 0.94 & 0.42 & 1.15 & -1.06 & 0.36 & -0.76 \\
\hline & HG & -0.10 & 0.05 & 0.39 & 0.73 & 0.78 & -0.10 & -1.16 & 1.76 & 0.36 & 0.07 \\
\hline & ED & -0.30 & -0.64 & 0.04 & 1.20 & -0.70 & 0.67 & 0.52 & -0.54 & -1.13 & -0.47 \\
\hline & EL & -0.11 & -1.04 & -0.34 & -0.09 & -0.74 & 0.18 & 0.47 & -1.32 & 0.04 & -1.04 \\
\hline & DM & 0.90 & -0.23 & 0.29 & -0.04 & 0.28 & -0.94 & 0.65 & -0.08 & 0.15 & -0.40 \\
\hline & $\mathrm{CC}$ & $0.92 * *$ & $0.74^{* *}$ & $0.68^{* *}$ & $0.51^{\text {ns }}$ & $0.20^{\mathrm{ns}}$ & $0.90 * *$ & $0.77^{* *}$ & $0.53^{\mathrm{ns}}$ & $0.49^{\mathrm{ns}}$ & $0.34^{\mathrm{ns}}$ \\
\hline & DF & 35 & 24 & 15 & 8 & 3 & 35 & 24 & 15 & 8 & 3 \\
\hline & $x^{2}$ & 194.6 & 93.7 & 51.5 & 18.2 & 2.1 & 175.9 & 88.2 & 39.2 & 21.2 & 6.7 \\
\hline
\end{tabular}

CC: canonical correlations; DF: degrees of freedom. AGRO—GY: grain yield; PE: popping expansion; PR: prolificacy; HG: 100-grain mass; ED: ear diameter; EL: ear length and DM: dry matter. SPAD index-S1, S2, S3, S4, and S5 $=$ SPAD readings at 17, 22, 29, 36, and 42 days after male anthesis, respectively. Symbols ns, ${ }^{* *}$ represent not significant, significant at $1.0 \%$ probability. 
Under WW condition, and considering the AGRO and SPAD index groups of traits, the first canonical pair $(r=0.90)$ associated the measurements $\mathrm{S}_{1}(17 \mathrm{DAA}), \mathrm{S}_{5}(42 \mathrm{DAA})$, and $\mathrm{S}_{4}(36 \mathrm{DAA})$ with the variables ED and DM. The $S_{1}$ and $S_{5}$ relationships occurred in the same direction of ED and in the opposite direction of DM, while $\mathrm{S}_{4}$ related itself in the opposite direction of ED and in the same direction of DM. The second canonical pair $(r=0.77)$ indicates the association of measurements $S_{1}$, $\mathrm{S}_{5}$, and $\mathrm{S}_{2}(22 \mathrm{DAA})$ with the variables HG and PR. The measurements $\mathrm{S}_{1}$ and $\mathrm{S}_{5}$ related themselves in the same direction with PR, but in the opposite direction with $H G$, while $S_{2}$ presented an inverse relationship with the traits PR and HG (Table 2).

In the canonical correlation estimated between the groups of traits, AGRO and ROOT, under WS condition, the first three canonical pairs were significant, with values of $r=0.89, r=0.84$, and $r=0.65$, from the first to the third pair, respectively. In this condition, the first canonical pair indicates that the lower the BN, the lower the PE and DM and the higher the ED. The second canonical pair points to lower PR and higher PE concomitant with lower DB and higher CD. The third canonical pair showed inverse correlation between BA and DM (Table 3).

Table 3. Correlation and coefficients of canonical pairs estimated between roots morphology and agronomic traits in 20 popcorn inbred lines under two different water conditions.

\begin{tabular}{|c|c|c|c|c|c|c|c|c|c|c|c|c|c|}
\hline & & \multicolumn{12}{|c|}{ Canonical Pairs } \\
\hline \multicolumn{2}{|c|}{ Traits } & \multicolumn{6}{|c|}{ Water-Stressed } & \multicolumn{6}{|c|}{ Well-Watered } \\
\hline & & 1st & 2nd & $3 r d$ & 4th & 5 th & 6th & 1st & 2nd & 3rd & 4th & 5 th & 6th \\
\hline \multirow{6}{*}{$\begin{array}{l}\stackrel{0}{0} \\
\stackrel{0}{0}\end{array}$} & BN & -0.71 & 0.40 & -1.59 & 0.44 & 0.01 & 0.20 & -0.26 & -0.01 & 0.86 & -0.30 & -0.01 & 0.34 \\
\hline & BA & -0.34 & 0.48 & 0.93 & 0.72 & 0.92 & 0.58 & -0.49 & 1.42 & 0.26 & 0.38 & 0.39 & -0.88 \\
\hline & BD & 0.32 & -0.94 & 0.05 & 1.27 & -1.47 & 0.20 & 0.32 & 0.33 & 0.38 & 0.95 & 0.49 & 0.03 \\
\hline & $\mathrm{CN}$ & 0.37 & -0.05 & -0.25 & -0.34 & -0.21 & 0.96 & 0.71 & 0.06 & 0.23 & -0.42 & 0.24 & -0.61 \\
\hline & CA & 0.07 & 0.28 & 0.01 & -1.10 & -0.96 & -1.00 & -0.21 & -1.47 & -0.48 & -0.61 & 0.39 & 0.90 \\
\hline & $\mathrm{CD}$ & 0.25 & 1.59 & -0.32 & -0.80 & 1.20 & -0.29 & 0.41 & 0.39 & -0.38 & -0.76 & -0.04 & 0.52 \\
\hline \multirow{7}{*}{ 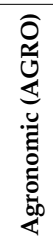 } & GY & -0.42 & -0.16 & 0.10 & -1.27 & 1.04 & 1.11 & 0.02 & 1.21 & 0.47 & 1.97 & 0.18 & 1.17 \\
\hline & PE & -0.89 & 0.97 & -0.50 & 0.56 & 0.37 & -0.07 & -0.12 & 0.13 & -0.73 & 0.59 & -0.68 & 0.34 \\
\hline & PR & 0.18 & -0.37 & 0.59 & 0.84 & 0.40 & -0.02 & -0.64 & -0.28 & -0.52 & -1.60 & -0.40 & 0.10 \\
\hline & HG & 0.22 & -1.12 & 0.34 & 0.05 & 0.14 & -0.90 & 0.70 & 0.27 & -0.17 & 1.68 & 0.10 & 0.45 \\
\hline & ED & 0.94 & 0.38 & -0.43 & 0.53 & -0.88 & -0.43 & 0.61 & -0.70 & -0.28 & -0.80 & 0.09 & 0.07 \\
\hline & EL & 0.17 & -0.16 & 0.19 & 0.55 & -1.58 & 0.13 & -0.66 & -1.48 & -0.27 & -1.10 & -0.36 & -0.22 \\
\hline & DM & -0.63 & -0.43 & -0.84 & 0.33 & 0.64 & -0.15 & 0.09 & 0.11 & 0.59 & -0.58 & -0.75 & -0.30 \\
\hline \multirow{3}{*}{\multicolumn{2}{|c|}{$\begin{array}{l}\text { CC } \\
\text { DF } \\
x^{2}\end{array}$}} & $0.89 * *$ & $0.84^{* *}$ & $0.65^{* *}$ & $0.52^{\mathrm{ns}}$ & $0.44^{\mathrm{ns}}$ & $0.13^{\mathrm{ns}}$ & $0.88^{* *}$ & $0.82 * *$ & $0.68^{* *}$ & $0.55^{\mathrm{ns}}$ & $0.36^{\mathrm{ns}}$ & $0.22^{\mathrm{ns}}$ \\
\hline & & 42 & 30 & 20 & 12 & 6 & 2 & 42 & 30 & 20 & 12 & 6 & 2 \\
\hline & & 203.2 & 121.8 & 58.0 & 28.9 & 12.5 & 0.9 & 201.9 & 121.4 & 62.2 & 29.4 & 10.3 & 2.6 \\
\hline
\end{tabular}

Under WW condition, the canonical correlations estimated between the AGRO and ROOT groups showed significance in the first $(r=0.8)$, second $(r=0.82)$, and third $(r=0.68)$ canonical pair. As per the first canonical pair, the higher the CN, the lower the HG and EL, and the higher the ED and PR. The second canonical pair showed that the higher the BA, the higher will be GY and the lower will be ED and EL, while the third canonical pair suggested a decrease in PE in plants with lower BN (Table 3).

\section{Discussion}

The soil water limitation strongly affected the traits GY (-55.3\%), PE (-28.8\%), and HG $(-23.5 \%)$. Scientific studies assign GY reduction, under drought conditions, to a smaller number of grains yielded per area [19]. The water stress in the soil, throughout anthesis phase, critical period for the crop [38,39], affects the viability of the pollen grain, stigma receptivity, and fertilization [40], resulting in a lower number of grains yielded. In this study, the reduction in GY is explained by the decrease in HG. In WS condition, the insufficiency of photoassimilates for grain filling was pointed out as the cause for the smaller size of these structures [18]. In the evaluation of popcorn hybrids under soil water stress, it was noted, on average, 30\% reduction in HG [41]. Prolificacy (-15.7\%), ear diameter ( $-4.1 \%)$, ear length 
$(-0.8 \%)$, and dry matter $(-14.8 \%)$ traits experienced the impact of soil water limitation to a lesser extent. Irrigation was interrupted 15 days before the male anthesis, in which the plants are at the end of their plant development, starting the emission of tassels. Hence, traits like PR, ED, EL, and DM, developed before the anthesis, tend to be less impacted, as they are already partially developed [39]. Durães et al., 2004 [39] described that, in the pre-flowering period, the plants have already reached or are close to the end of the plant development. It should be stated that, in maize, PR presents a high genetic correlation with GY, both under adequate water conditions of growing [42] and under stress conditions [43], being used as a selection trait in breeding programs for WS conditions.

SPAD index (leaf greenness), generated by the evaluation of a portable chlorophyll meter (SPAD), turned out to be a trait of high potential for genotypic discrimination in materials evaluated under different water conditions. At 17 DAA, when the first measurement was taken, differences between genotypes and environments were observed. Moreover, SPAD index decreases faster under WS conditions $[13,23,24]$, because the leaf senescence occurs more sharply under WS in comparison with the WW condition. The foliar senescence is coordinated by reproductive plant stadium, but also strongly influenced by the environment [44]. Thus, SPAD index is an essential tool for diagnosing plant stress [13,23-25]. Actually, spectrometric methods are efficient to evaluate the different water conditions and the performance of cereals [45].

SPAD index measurements suggest a photosynthetic capacity of the leaf tissues, since that this index is correlated with chlorophyll concentration, and enable to obtain better inferences of photosynthesis [25]. Kamphorst et al. (2020) [46] evaluated SPAD values popcorn inbred lines contrasted to grain yield in drought conditions. The authors showed that maximum SPAD values were obtained more later (11 days after anthesis) in WW, when compared with WS (two days after anthesis). Maximum SPAD index values are related to late leaf senescence, due to high chlorophyll concentration and photosynthetic carbon assimilation [46]. In addition, Gregersen (2008) [47], showed that nutrients mobilization from senescent leaves to reproductive organs are important to plant growth in drought conditions. Actually, Killi et al. (2017) [48] evaluated maize varieties with contrasting drought tolerance in water-stressed condition and showed no physiological or morphological traits that may be associated with enhanced yield in the drought tolerant maize variety. As such, the respective yield characteristics of the drought and sensitive maize varieties may be the result of differences in the partitioning of photosynthate between reproduction and vegetative structures [48].

Plants increased the brace root and crown density, displaying the phenotypic root plasticity of adaptive response to WS condition. Maize plants with reduced lateral root branching make greater axial root elongation possible, and the greater depth of rooting promotes water acquisition in deeper layers of dry soils [49]. Because of these characteristics, the metabolic root demand of these genotypes is lower, which may contribute to higher growth, with consequent greater grain yield [50]. The drought tolerant maize varieties exhibited higher investment in root-systems, allowing greater uptake of the available soil water [48]. In this way, lower root density is important for drought tolerance and should be considered as a selection goal in maize breeding programs $[49,51]$.

The brace and crown root angles are directed more vertically towards the soil for the acquisition of water. Trachsel et al. (2011) [27] report that, in water-limited environments, genotypes with larger angles, close to $90^{\circ}$, of the roots in relation to the soil present adaptive advantages to find water. A root ideotype with three characteristics, Steep, Cheap, and Deep, may represent an advantage for water acquisition in deeper soil layers [29]. Steep suggests greater adaptive value to drought for plants with root angles close to $90^{\circ}$ in relation to the soil [29].

Agronomic and root traits suffered genotype $\times$ water condition interaction, which may make concomitant selection for WS and WW conditions difficult. A number of papers describe the presence of $\mathrm{G} \times \mathrm{WC}$ interaction between common maize traits evaluated with and without drought stress $[15,52]$. Plant breeders hardly ever select root traits because of the high plasticity in response to soil conditions and measurement difficulty, incurring in low heritability values [50]. 
Higher SPAD index was associated with higher yield values; in addition, these measurements can be reliable for plant selection considering the absence of genotype $\times$ water condition interaction in the present work. Researches in this area have focused on secondary morphological and physiological traits easy to measure under field conditions, which correlate with grain yield [19,20,23,39,53,54]. The use of secondary traits of simple measurement and high adaptive value can increase the efficiency of the selection under stressful condition [55]. A suitable secondary trait is that of high heritability, low cost, easy-to-measure, stable during the measurement period, and, above all, genetically associated with grain yield under stress conditions [56]. Additionally, in recurrent selection programs with maize, it has been said that the mean yield of tropical germplasm grains has increased after eight cycles, when genotypes with delayed leaf senescence were prioritized under intermediate and severe water stress conditions (rain-free winter season in Mexico) [16].

The choice of the appropriate phenological stage for SPAD index measurements is essential for consistent phenotyping of plants under drought conditions. In the view of Cairns et al. (2012) [19], the effective application of phenotyping methodologies relies, partly, on the applicability of these methodologies in the critical stages associated with grain yield. Accordingly, given the results presented herein, the evaluation in $S_{2}$ and $S_{4}$, under WS, and in $S_{1}$, under WW conditions, is recommended. The proper stage of evaluation to identify differences among genotypes by means of spectral indices is the phenological stage of grain filling $[10,19,20,23]$.

On the basis of an agronomic and root characterization and using different dates of measurement of the SPAD index, it was sought, in this research, to identify traits with variability and that do not present genotype $\times$ water condition $(G \times W C)$ interaction, but that present desirable associations for the traits GY and PE, to favor the indirect selection process of superior genotypes. Firstly, the ideal scenario would be the absence of $G \times$ WC interaction in relation to the traits GY and PE. A second promising scenario would be to find a variable associated with GY and PE in both environments. The third promising scenario would be to find a variable associated with GY and PE only in the environment under WS condition, but not presenting $\mathrm{G} \times \mathrm{WC}$, and which would consequently have the role of ensuring a reliable selection of drought tolerant genotypes in the environment under WW condition. These scenarios were not observed.

Considering the results of the agronomic traits, the $\mathrm{G} \times \mathrm{WC}$ interactions proved to be an obstacle for the selection of high productive genotypes under drought by direct via. In addition to the traits GY and PE have significant $G \times W C$ interaction, the traits that did not present $G \times W C$ interaction (HG, EL, and DM) expressed either weak or negative correlation with PE (Figure 2). Similar to the agronomic traits, the root traits expressed significant $G \times W C$ interaction for all their variables, making their use in indirect selection in an irrigation environment unviable (Table 2), and although, under WS condition, the root traits $\mathrm{BN}$, in the first canonical pair, and $\mathrm{BD}$ and $\mathrm{CD}$, in the second canonical pair, are associated with $\mathrm{PE}$, their use is unviable because it is a destructive, indirect and costly measure [27].

The SPAD index did not present significant $G \times W C$ interaction in the evaluations from $S_{1}$ (17 DAA) to $S_{4}$ (36 DAA); hence, they have potential to be used in an environment under WW condition (Table 1). Regarding the root traits, the variables correlated similarly to what was verified by Trachsel et al. [27], which emphasize the association between the two pairs of root traits BA and CA, and DB and CD. When observed the Pearson linear correlation (Figure 2), however, the correlation between the measures of SPAD index and GY under WW condition were positive, while regarding PE, they were negative or weak. This emphasizes that selection for these two traits is a challenge already addressed by many authors, who have reported observing negative correlations between GY and PE [3,6,31,57].

Conversely, the $\mathrm{S}_{3}$ SPAD index values correlated negatively in the second and third canonical pairs with GY and PE, respectively (Table 2). Taking these two canonical pairs into account, the smaller the $\mathrm{S}_{3}$ (29 DAA), the greater the GY and PE. Even though the association in the second and third canonical pairs is less relevant in relation to the first one, the results of $S_{3}$ association should be considered.

Results of Pearson correlations and canonical correlations (CCA) were in contrast in various situations. However, Pearson linear correlation is a multiple univariate method, whereas CCA considers 
the interaction between groups of traits. In accordance with Thompson (2005) [33], the CCA better illustrates the reality of traits interacting with each other. For this reason, correlation patterns in CCA are sensitive to changes with the addition or exclusion of a simple variable.

Given that the root and SPAD index traits were well represented, it is assumed that the CCA should be regarded as a selection index for GY and PE increase. In findings from previous analysis, Kamphorst et al. (2019) [30] support this statement using the same genotypes because, as well as in this work, the research cited above concluded that SPAD index measures are associated with simultaneous increase of GY and PE under WS condition, but having as dependent variable the product of GY and PE, that is, volume of popcorn per hectare. Kamphorst et al. (2019) [30] performed a single SPAD index measurement at $35 \mathrm{DAF}$, equivalent to the $\mathrm{S} 4$ measurement, which, in this study, was negatively and with high intensity associated with PE in the third canonical pair and under WS condition. For this reason, CCA meets the need to better understand the relationship among traits and the choice of the best variable for efficient use in indirect selection.

The canonical correlation analysis in popcorn crops has great potential for use in identifying non-destructive and easily quantified traits, which are associated with GY and PE, especially as a result of the negative association between GY and PE proposed by some authors [3,6,31,57]. Even in relation to the path analysis, canonical correlations are of interest, as they allow analyzing the association between different groups of variables simultaneously and not only fixing a variable as dependent. According to the findings of this study and the characteristics of the variable that was highlighted as being optimal for the selection of the high productive genotypes under drought by indirect via, it proved to be possible to identify variables with potential for use in indirect selection or even to compose a selection index for the discrimination of the high productive genotypes under water stress condition based on well-watered condition. The SPAD index, measured at 29 DAA, was significant because it associated grain yield and popping expansion in an environment with limited soil water conditions, as well as the measurements at 22 and 36 DAA, which combined more closely with grain yield.

\section{Conclusions}

Major guidance has been given regarding the most adequate traits for the development of research correlated to water shortage in popcorn in regard to the determination of the proper phenological stages for measurement. The leaf senescence, estimated by SPAD index, can be applied to identify more productive genotypes under drought conditions, resulting from a non-destructive procedure using a portable chlorophyll meter (SPAD) [14,20,58].

Author Contributions: Conceptualization, S.H.K. and V.J.d.L.; methodology, S.H.K, G.M.B.G., A.T.d.A.J., V.J.d.L., J.T.L., K.F.M.S., and D.R.d.S.J.; software, S.H.K. and G.M.B.G.; validation, S.H.K.; formal analysis, S.H.K, G.M.B.G., and V.J.d.L.; investigation, S.H.K., G.M.B.G., A.T.d.A.J., V.J.d.L., J.T.L., K.F.M.S., D.R.d.S.J., J.S.S., F.T.d.O., C.C.G.C., and W.P.R.; resources, S.H.K.; data curation, S.H.K.; writing-original draft preparation, S.H.K., G.M.B.G., A.T.d.A.J., V.J.d.L., J.S.S., F.T.d.O., W.P.R., and E.C.; writing-review and editing, S.H.K., G.M.B.G., A.T.d.A.J., V.J.d.L., and E.C.; supervision, A.T.d.A.J. and E.C.; project administration, S.H.K.; funding acquisition, S.H.K., A.T.d.A.J., W.P.R., and E.C. All authors have read and agreed to the published version of the manuscript.

Funding: This study was financed in part by the Coordenação de Aperfeiçoamento de Pessoal de Nível Superior - Brasil (CAPES)-Finance Code 001. Funding was also provided by FAPERJ, with the project E26/201.813/2017 to S.H.K., E-26/202.323/2017 to W.P.R., E-26/202.759/2018 to E.C., E26/202.761/2017 to A.T.do A.J and fellowships awarded 303166/2019-3, E.C. (CNPq) and FAPEMA (Fundação de Amparo à Pesquisa e ao Desenvolvimento Científico e Tecnológico do Maranhão) (PVS 00583/20, E.C) and FAPEMA (Fundação de Amparo à Pesquisa e ao Desenvolvimento Científico e Tecnológico do Maranhão) (PVS 00583/20, E.C).

Conflicts of Interest: The authors declare no conflict of interest. 


\section{References}

1. Freitas, S.P., Jr.; Amaral Juniot, A.T.; Rangel, R.M.; Viana, A.P. Genetic gains in popcorn by full-sib recurrent selection. Crop. Breed. Appl. Biotechnol. 2009, 9, 1-7. [CrossRef]

2. Amaral Junior, A.T.; Gonçalves, L.S.A.; Freitas, S.D.P., Jr.; Candido, L.S.; Vittorazzi, C.; Pena, G.F.; Ribeiro, R.M.; Silva, T.R.D.C.; Pereira, M.G.; Scapim, C.A.; et al. UENF 14: A new popcorn cultivar. Crop Breed. Appl. Biotechnol. 2013, 13, 218-220.

3. De Lima, V.J.; do Amaral, A.T., Jr.; Kamphorst, S.H.; Pena, G.F.; Leite, J.T.; Schmitt, K.F.; Vittorazzi, C.; de Almeida Filho, J.E.; Mora, F. Combining ability of $S_{3}$ progenies for key agronomic traits in popcorn: Comparison of testers in top-crosses. Genet. Mol. Res. 2016, 15. [CrossRef] [PubMed]

4. Dos Santos, A.; do Amaral Junior, A.T.; Kamphorst, S.H.; Gonçalves, G.M.B.; Santos, P.H.A.D.; Silva Vivas, J.M.; Sousa Mafra, G.; Khan, S.; Tomaz de Oliveira, F.; Schmitt, K.F.M.; et al. Evaluation of Popcorn Hybrids for Nitrogen Use Efficiency and Responsiveness. Agronomy 2020, 10, 485. [CrossRef]

5. Mafra, G.S.; do Amaral Junior, A.T.; de Almeida Filho, J.E.; Vivas, M.; Santos, P.H.A.D.; Santos, J.S.; Pena, G.F.; Lima, V.J.d.; Kamphorst, S.H.; de Oliveira, F.T.; et al. SNP-based mixed model association of growth- and yield-related traits in popcorn. PLoS ONE 2019, 14, e218552. [CrossRef]

6. Cabral, P.D.S.; do Amaral, A.T., Jr.; de Freitas, I.L.J.; Ribeiro, R.M.; da Silva, T.R.C. Cause and effect of quantitative characteristics on grain expansion capacity in popcorn. Rev. Ciênc. Agronôm. 2016, 47, 108-117. [CrossRef]

7. Kist, B.B.; de Carvalho, C.; Beling, R.R. Anuário Brasileiro do Milho 2019; Beling, R.R., Ed.; Editora Gazeta: Santa Cruz do Sul, Brazil, 2019; ISBN 1808-3439.

8. Awange, J.L.; Mpelasoka, F.; Goncalves, R.M. When every drop counts: Analysis of Droughts in Brazil for the 1901-2013 period. Sci. Total Environ. 2016, 566-567, 1472-1488. [CrossRef]

9. Van Loon, A.F.; Gleeson, T.; Clark, J.; Van Dijk, A.I.J.M.; Stahl, K.; Hannaford, J.; Di Baldassarre, G.; Teuling, A.J.; Tallaksen, L.M.; Uijlenhoet, R.; et al. Drought in the Anthropocene. Nat. Geosci. 2016, 9, 89-91. [CrossRef]

10. Adebayo, M.A.; Menkir, A.; Hearne, S.; Kolawole, A.O. Gene action controlling normalized difference vegetation index in crosses of elite maize (Zea mays L.) inbred lines. Cereal Res. Commun. 2017, 45, 675-686. [CrossRef]

11. Wang, W.; Vinocur, B.; Altman, A. Plant responses to drought, salinity and extreme temperatures: Towards genetic engineering for stress tolerance. Planta 2003, 218, 1-14. [CrossRef]

12. Ghannoum, O. C4 photosynthesis and water stress. Ann. Bot. 2008, 103, 635-644. [CrossRef]

13. Romano, G.; Zia, S.; Spreer, W.; Sanchez, C.; Cairns, J.; Luis, J.; Müller, J. Use of thermography for high throughput phenotyping of tropical maize adaptation in water stress. Comput. Electron. Agric. 2011, 79, 67-74. [CrossRef]

14. Araus, J.L.; Kefauver, S.C.; Zaman-Allah, M.; Olsen, M.S.; Cairns, J.E. Translating High-Throughput Phenotyping into Genetic Gain. Trends Plant Sci. 2018, 23, 451-466. [CrossRef] [PubMed]

15. Dias, K.O.D.G.; Gezan, S.A.; Guimarães, C.T.; Parentoni, S.N.; Guimarães, P.E.D.O.; Carneiro, N.P.; Portugal, A.F.; Bastos, E.A.; Cardoso, M.J.; Anoni, C.D.O.; et al. Estimating Genotype $\times$ Environment Interaction for and Genetic Correlations among Drought Tolerance Traits in Maize via Factor Analytic Multiplicative Mixed Models. Crop Sci. 2018, 58, 72. [CrossRef]

16. Bolaños, J.; Edmeades, G.O. Eight cycles of selection for drought tolerance in lowland tropical maize. I. Responses in grain yield, biomass, and radiation utilization. Field Crop. Res. 1993, 31, 233-252. [CrossRef]

17. Tollenaar, M.; Ahmadzadeh, A.; Lee, E.A. Physiological Basis of Heterosis for Grain Yield in Maize. Crop Sci. 2004, 44, 2086. [CrossRef]

18. Araus, J.L.; Sánchez, C.; Cabrera-Bosquet, L. Is heterosis in maize mediated through better water use? New Phytol. 2010, 187, 392-406. [CrossRef] [PubMed]

19. Cairns, J.E.; Sanchez, C.; Vargas, M.; Ordoñez, R.; Araus, J.L. Dissecting Maize Productivity: Ideotypes Associated with Grain Yield under Drought Stress and Well-watered Conditions. J. Integr. Plant Biol. 2012, 54, 1007-1020. [CrossRef]

20. Adebayo, M.A.; Menkir, A.; Blay, E.; Gracen, V.; Danquah, E.; Hearne, S. Genetic analysis of drought tolerance in adapted $\times$ exotic crosses of maize inbred lines under managed stress conditions. Euphytica 2014, 196, 261-270. [CrossRef] 
21. Joshi, A.K.; Kumari, M.; Singh, V.P.; Reddy, C.M.; Kumar, S.; Rane, J.; Chand, R. Stay green trait: Variation, inheritance and its association with spot blotch resistance in spring wheat (Triticum aestivum L.). Euphytica 2006, 153, 59-71. [CrossRef]

22. Costa, E.F.N.; Santos, M.F.; Moro, G.V.; Alves, G.F.; de Souza Junior, C.L. Herança da senescência retardada em milho. Pesqui. Agropecu. Bras. 2008, 43, 207-213. [CrossRef]

23. Zia, S.; Romano, G.; Spreer, W.; Sanchez, C.; Cairns, J.; Araus, J.L.; Müller, J. Infrared Thermal Imaging as a Rapid Tool for Identifying Water-Stress Tolerant Maize Genotypes of Different Phenology. J. Agron. Crop Sci. 2013, 199, 75-84. [CrossRef]

24. Araus, J.L.; Serret, M.D.; Edmeades, G.O. Phenotyping maize for adaptation to drought. Front. Physiol. 2012, 3, 1-20. [CrossRef] [PubMed]

25. De Castro, F.A.; Campostrini, E.; Netto, A.T.; De Menezes De Assis Gomes, M.; Ferraz, T.M.; Glenn, D.M. Portable chlorophyll meter (PCM-502) values are related to total chlorophyll concentration and photosynthetic capacity in papaya (Carica papaya L.). Theor. Exp. Plant Physiol. 2014, 26, 201-210. [CrossRef]

26. Lynch, J. Root Architecture and Plant Productivity. Plant Physiol. 1995, 109, 7-13. [CrossRef]

27. Trachsel, S.; Kaeppler, S.M.; Brown, K.M.; Lynch, J.P. Shovelomics: High throughput phenotyping of maize (Zea mays L.) root architecture in the field. Plant Soil 2011, 341, 75-87. [CrossRef]

28. Hund, A.; Ruta, N.; Liedgens, M. Rooting depth and water use efficiency of tropical maize inbred lines, differing in drought tolerance. Plant Soil 2009, 318, 311-325. [CrossRef]

29. Gao, Y.; Lynch, J.P. Reduced crown root number improves water acquisition under water deficit stress in maize (Zea mays L.). J. Exp. Bot. 2016, 67, 4545-4557. [CrossRef]

30. Kamphorst, S.H.; do Amaral, A.T., Jr.; de Lima, V.J.; Guimarães, L.J.M.; Schmitt, K.F.M.; Leite, J.T.; Santos, P.H.A.D.; Chaves, M.M.; Mafra, G.S.; dos Santos, D.R., Jr.; et al. Can Genetic Progress for Drought Tolerance in Popcorn Be Achieved by Indirect Selection? Agronomy 2019, 9, 792. [CrossRef]

31. Do Amaral, A.T., Jr.; dos Santos, A.; Gerhardt, I.F.S.; Kurosawa, R.N.F.; Moreira, N.F.; Pereira, M.G.; Gravina, G.A.; Silva, F.H.L. Proposal of a super trait for the optimum selection of popcorn progenies based on path analysis. Genet. Mol. Res. 2016, 15, 1-9. [CrossRef]

32. Hardoon, D.R.; Szedmak, S.; Shawe-Taylor, J. Canonical Correlation Analysis: An Overview with Application to Learning Methods. Neural Comput. 2004, 16, 2639-2664. [CrossRef] [PubMed]

33. Thompson, B. Canonical Correlation Analysis. In Encyclopedia of Statistics in Behavioral Science; John Wiley \& Sons, Ltd.: Chichester, UK, 2005.

34. Vittorazzi, C.; Júnior, A.T.A.; Guimarães, A.G.; Silva, F.H.L.; Pena, G.F.; Daher, R.F.; Gerhardt, I.F.S.; Oliveira, G.H.F.; Santos, P.H.A.D.; Souza, Y.P.; et al. Evaluation of genetic variability to form heterotic groups in popcorn. Genet. Mol. Res. 2018, 17. [CrossRef]

35. Christensen, H.K.; Montgomery, C.A. Corporate economic performance: Diversification strategy versus market structure. Strateg. Manag. J. 1981, 2, 327-343. [CrossRef]

36. Cruz, C.D. GENES-A software package for analysis in experimental statistics and quantitative genetics. Acta Sci. Agron. 2013, 35, 271-276. [CrossRef]

37. Cruz, C.D.; Regazzi, A.J.; Carneiro, P.C.S. Modelos Biométricos Aplicados ao Melhoramento Genético; UFV: Viçosa, Brazil, 2012; ISBN 9788572694339.

38. De Sousa Mendes, W.; Drews, T.A.; Medeiros, J.C.; Dalla Rosa, J.; Gualberto, A.V.; Mielezrski, F. Development and productivity of maize in response to spatial arrangement under semiarid condition of Northeastern Brazil. Aust. J. Crop Sci. 2017, 11, 313-321. [CrossRef]

39. Durães, F.O.M.; dos Santos, M.X.; Gama, E.E.G.; Magalhães, P.C.; Albuquerque, P.E.P.; Guimarães, C.T. Fenotipagem Associada a Tolerância a Seca em Milho para Uso em Melhoramento, Estudos Genômicos e Seleção Assistida por Marcadores. Embrapa Milho Sorgo Circ. Téc. INFOTECA-E 2004, 39, 18.

40. Zinselmeier, S.A.; Lauer, M.J.; Boyer, J.S. Reversing Drought-Induced Losses in Grain Yield: Sucrose Maintains Embryo Growth in Maize. Crop Sci. 1995, 35, 1390. [CrossRef]

41. De Lima, V.J.; do Amaral, A.T., Jr.; Kamphorst, S.H.; Bispo, R.B.; Leite, J.T.; de Santos, T.O.; Schmitt, K.F.M.; Chaves, M.M.; de Oliveira, U.A.; Santos, P.H.A.D.; et al. Combined Dominance and Additive Gene Effects in Trait Inheritance of Drought-Stressed and Full Irrigated Popcorn. Agronomy 2019, 9, 782. [CrossRef]

42. Lima Neto, F.P.; Souza, C.L., Jr. De Number of recombinations and genetic properties of a maize population undergoing recurrent selection. Sci. Agric. 2009, 66, 52-58. [CrossRef] 
43. Li, X.-H.; Liu, X.-D.; Li, M.-S.; Zhang, S.-H. Identification of quantitative trait loci for anthesis-silking interval and yield components under drought stress in maize. Acta Bot. Sin. 2003, 45, 852-857.

44. Combe, L.; Escobar-Gutiérrez, A.J. Sénescence d'un pied de maïs: Évolution de la floraison à la récolte. Botany 2009, 87, 1036-1053. [CrossRef]

45. Yousfi, S.; Gracia-Romero, A.; Kellas, N.; Kaddour, M.; Chadouli, A.; Karrou, M.; Araus, J.L.; Serret, M.D. Combined Use of Low-Cost Remote Sensing Techniques and $813 \mathrm{C}$ to Assess Bread Wheat Grain Yield under Different Water and Nitrogen Conditions. Agronomy 2019, 9, 285. [CrossRef]

46. Kamphorst, S.H.; do Amaral, A.T., Jr.; de Lima, V.J.; Diniz, S.P.H.A.; Rodrigues, W.P.; Silva, V.J.M.; Gonçalves, G.M.B.; Schmitt, K.F.M.; Leite, J.T.; Vivas, M.; et al. Comparison of selection traits for effective popcorn breeding under water limiting conditions. Front. Plant Sci. 2020, 11, 1-19. [CrossRef] [PubMed]

47. Gregersen, P.L.; Holm, P.B.; Krupinska, K. Leaf senescence and nutrient remobilisation in barley and wheat. Plant Biol. 2008, 10, 37-49. [CrossRef] [PubMed]

48. Killi, D.; Bussotti, F.; Raschi, A.; Haworth, M. Adaptation to high temperature mitigates the impact of water deficit during combined heat and drought stress in C3 sunflower and C4 maize varieties with contrasting drought tolerance. Physiol. Plant 2017, 159, 130-147. [CrossRef] [PubMed]

49. Zhan, A.; Schneider, H.; Lynch, J.P. Reduced Lateral Root Branching Density Improves Drought Tolerance in Maize. Plant Physiol. 2015, 168, 1603-1615. [CrossRef] [PubMed]

50. Lynch, J.P. Root phenes that reduce the metabolic costs of soil exploration: Opportunities for 21st century agriculture. Plant Cell Environ. 2015, 38, 1775-1784. [CrossRef]

51. Kamphorst, S.H.; de Lima, V.J.; Schimitt, K.F.M.; Leite, J.T.; Azeredo, V.C.; Pena, G.F.; Santos, P.H.A.D.; Júnior, D.R.S.; da Silva Júnior, S.B.; Bispo, R.B.; et al. Water stress adaptation of popcorn roots and association with agronomic traits. Genet. Mol. Res. 2018, 17, 1-14. [CrossRef]

52. Maazou, A.-R.S.; Tu, J.; Qiu, J.; Liu, Z. Breeding for Drought Tolerance in Maize (Zea mays L.). Am. J. Plant Sci. 2016, 7, 1858-1870. [CrossRef]

53. Santos, M.X.; Andrade, C.L.T.; Oliveira, A.C.; Leite, C.E.P.; Carvalho, H.W.L.; Gama, E.E.G.; Pacheco, C.A.P.; Gumarães, P.E.O.; Parentoni, S.N. Comportamento de Híbridos de Milho Selecionados e não Selecionados para Asi sob Estresse de Água no Florescimento e no Enchimento de Grãos. Rev. Bras. Milho Sorgo 2003, 2, 71-81. [CrossRef]

54. Câmara, T.M.M.; Bento, D.A.V.; Alves, G.F.; Santos, M.F.; Moreira, J.U.V.; Souza, C.L., Jr. De Parâmetros genéticos de caracteres relacionados à tolerância à deficiência hídrica em milho tropical. Bragantia 2007, 66, 595-603. [CrossRef]

55. Hallauer, A.R.; Carena, M.J.; Miranda Filho, J.B. Quantitative Genetics in Maize Breeding; Springer: New York, NY, USA, 2010.

56. Edmeades, G.O.; Bolaños, J.; Chapman, S.C.; Lafitte, H.R.; Banziger, M. Selection Improves Drought Tolerance in Tropical Maize Populations. Crop Sci. 1999, 39, 1306. [CrossRef]

57. Pereira, M.G.; Amaral, A.T., Jr. Estimation of Genetic Components in Popcorn Based on the Nested Design. Crop Breed. Appl. Biotechnol. 2001, 1, 3-10. [CrossRef]

58. Lu, Y.; Hao, Z.; Xie, C.; Crossa, J.; Araus, J.; Gao, S.; Vivek, B.S.; Magorokosho, C.; Mugo, S.; Makumbi, D.; et al. Field Crops Research Large-scale screening for maize drought resistance using multiple selection criteria evaluated under water-stressed and well-watered environments. Field Crop. Res. 2011, 124, 37-45. [CrossRef]

(C) 2020 by the authors. Licensee MDPI, Basel, Switzerland. This article is an open access article distributed under the terms and conditions of the Creative Commons Attribution (CC BY) license (http://creativecommons.org/licenses/by/4.0/). 